\title{
PROBLEMS OF FALSE MEDICINES' DISTRIBUTION AND PROSPECTS OF COMBAT: SURVEY OF SPECIALISTS AND CONSUMERS RESULTS
}

\author{
Serhii Lebed, Alla Nemchenko
}

The aim: comparative analysis of the results of a questionnaire survey of pharmaceutical and medical professionals and consumers, conducted by the authors during 2019-2021 to identify opinions on which there are coincidences and differences, as well as an assessment of the problem of drug counterfeiting in Ukraine to develop approaches to prevent their spread.

Materials and methods. The study used scientific publications, as well as the results of a survey of specialists of the State Service of Ukraine for Medicines and Drug Control (State Medical Service) and its territorial bodies, pharmaceutical and medical professionals of health care institutions and consumers on the fight against drug falsification. The research was conducted using the methods of questionnaires, systematization and generalization.

Results. According to the results of a comprehensive questionnaire during 2019-2021, it was found that the share of CM in the Ukrainian pharmaceutical market is estimated at $5 \%$ by a majority of respondents on average $58.5 \%$, including $59.7 \%$ of experts of the State Medical Service, $42.3 \%$ of pharmacy specialists, $11.4 \%$ by doctors and $73.5 \%$ by consumers. Respondents' answers about the signs of drug falsification differ significantly, so most experts believe that this is a change in the usual signs (taste, smell, color), while pharmacy specialists - labelling in a foreign language, doctors - no therapeutic effect, for consumers it is a change in packaging design (labels) and a significantly lower price. The main sales channels of CM for experts and pharmacy specialists are e-commerce (68.7 \% and $75.7 \%$, respectively), while the majority of consumers could not determine.

Many experts and pharmacy specialists pointed to the need to introduce special security features of packaging in the form of $2 d$ barcodes as the main method for protection and detection of CM (79.1\% and 39.6\%, respectively). Most of the surveyed pharmacy workers and consumers believe that the risk of purchasing counterfeit drugs is higher in the pharmacies of individual entrepreneurs or small pharmacy chains.

The main problem that hinders the effective fight against drug counterfeiting was the imperfect legislation (68.7 \%). Regarding effective tools in the fight against counterfeit drugs, experts called a significant strengthening of the powers of the regulatory body - following the example of the FDA (70.1\%).

Conclusions. It is established that the most important priorities of the state policy for combating CM in Ukraine are the improvement of the system of state control and quality assurance of medicines, in particular $2 d$ coding, as well as the need to strengthen the responsibility for drug falsification. The results of research on the problem of drug falsification indicate the feasibility of introducing a systematic survey for a wider range of respondents - professionals and consumers

Keywords: falsification, medicines, questionnaires, expert evaluation, efficiency, experts, pharmaceutical specialists, doctors, consumers

How to cite:

Lebed, S., Nemchenko, A. (2021). Problems of false medicines' distribution and prospects of combat: survey of specialists and consumers results. ScienceRise: Pharmaceutical Science, 5 (33), 49-56. doi: http://doi.org/10.15587/2519-4852.2021.243240

(C) The Author(s) 2021

This is an open access article under the Creative Commons CC BY license hydrate

\section{Introduction}

According to the report of the European Union Intellectual Property Office on trade in counterfeit pharmaceutical products (The Organization for Economic Cooperation and Development and the European Union Intellectual Property Office on Trade in Counterfeit Pharmaceutical Products), the global level of trade in counterfeit medicines (CM) in 2016 reached 4.4 billion dollars [1]. During operation "Pangea", a raid against organized crime in March 2020, Europol seized four million packages of various counterfeit drugs and about 34,000 counterfeit surgical masks. Among the counterfeit drugs were antiviral drugs, antimalarial drug chloroquine, as well as dietary supplements and vitamin drugs [2].

At a time when the Covid-19 epidemic poses unprecedented challenges to the health sector, the Council of Europe is urging governments to be extremely vigilant about counterfeit or CM and medical devices. Unfortunately, little is known about the true impact on public health and the socio-economic impact of substandard and counterfeit pharmaceuticals. A strong evidence base is needed to help prevent, detect and respond to counterfeit medicines and medical devices and the threat to public health they pose [3]. 
That is why the understanding of experts of national regulatory authorities, practitioners in the field of medicine and pharmacy and consumers of drugs is extremely important for the development of methods to effectively combat the spread of counterfeit products.

Various scientists are constantly studying the problem of drug falsification, finding ways and methods to prevent their spread. Thus, in particular, in the article [4] the authors investigated the mobile applications available on the communications market, which allow to detect counterfeit products. In the publication [5] the authors proposed to use the concept of CounterChain - a technology based on blockchain, to implement a unified solution that provides broad control of the supply chain of drugs and increase consumer safety.

Article [6] proposes to introduce authentication of each dose of the drug to increase the digital level of security of pharmaceutical companies, as the main problem of serialization ( $2 \mathrm{~d}$ coding) is that it is aimed primarily at secondary packaging and could not be used directly on tablets.

In his publication [7] the author draws attention to the fact that to detect $\mathrm{CM}$ it is advisable to actively involve consumers of pharmaceutical products. Most of them are unlikely to report CM problems due to fears of privacy breaches, which may indicate that complications and deaths from the use of counterfeit and substandard drugs purchased, for example, outside the network of legal pharmacies will not be tracked. no law enforcement or regulatory bodies.

The opinion of pharmacists about counterfeit drugs in Qatar was studied by scientists in the publication [8]. They concluded that one of the main factors leading to the spread of CM is the lack of sufficient information, knowledge and awareness of this problem in society. It should be noted that similar surveys were conducted, for example, in Sweden [9] and Kazakhstan [10].

Ukraine has taken certain steps to implement measures to combat the proliferation of counterfeit products, in particular to establish liability for the illicit trafficking of counterfeit medicines and medical devices. So, our country was one of the first to ratify without any restrictions the Council of Europe Convention of 28.10.2011 on counterfeiting of medical devices and similar crimes that threaten health care. The relevant law was adopted on June 7, 2012, in Ukraine the Convention entered into force on January 1, 2016 [11]. But a common and quite important part of the problem of combating drug counterfeiting in Ukraine, according to the authors, is the lack of state authorities to use on a regular basis methods of interviewing experts, manufacturers, importers, distributors, pharmacies, doctors, public professional associations and citizens on awareness of the problems of drug counterfeiting to form a conceptual model for the implementation of state policy to prevent drug counterfeiting.

Therefore, the aim of the research was a comparative analysis of the results of a survey of pharmaceutical and medical professionals and consumers to identify opinions that coincide and disagree, as well as assess the extent of the problem of drug counterfeiting in Ukraine to develop approaches to prevent their spread.

\section{Planning (methodology) of the study}

To achieve this goal, the following stages of research were proposed:

- analysis of scientific publications on a range of issues related to assessing the status and effectiveness of combating the spread of CM in Ukraine and the world, identifying current issues of drug counterfeiting and modern methods of combating their spread in the country and the world (Phase I - preparatory);

- development of 4 questionnaires to study the opinions of specialists of the State Medical Service of Ukraine and its territorial bodies, managers and specialists of pharmacies, doctors and consumers of drugs, justification of the required number of respondents, selection of respondents based on their purposeful choice (Phase II - methodological);

- determining the procedure for conducting questionnaires in each group of respondents, organizing the survey, collecting and preliminary analysis of completed questionnaires for each group of respondents (Phase III organizational);

- statistical processing of the received questionnaires, determination of statistical indicators that characterize the consistency of respondents' opinions separately for each group (Phase IV - statistical);

- critical evaluation of the results obtained within each group of respondents, as well as a comparative analysis of the opinions of pharmaceutical professionals, doctors and consumers, the search for points of contact and differences (Phase $\mathbf{V}$ - analytical);

- registration of the received results, definition of perspective directions of the research, preparation of materials in open access (Phase VI - summarizing).

Thus, the proposed design contains 6 stages, which reflect the peculiarities of conducting questionnaires in pharmacy, in particular the relevance of modern problems of CM spread.

\section{Materials and methods}

Quantitative estimates of CM volume in the pharmaceutical market, particularly in Ukraine, are contradictory, as official reporting cannot give a complete picture of shadow processes. According to the authors, it is possible to obtain objective data on these issues by conducting sample surveys of specialists and consumers. Similar pilot surveys on the problems of drug falsification, availability of information technology and awareness of specialists in the field of medicine and pharmacy were conducted in Qatar [8], Sweden [9], USA [12], Kazakhstan [10] and others.

Analysis of scientific publications [13-20] and practical experience in the research allowed to develop 4 questionnaires, which included data on respondents, as well as up to 21 questions in two sections on the assessment of the state and problems of combating the spread of CM. Respondents were offered, depending on the questions, from 1 to 9 answer options, and also provided options - another answer or I hesitate to answer. The questionnaire was conducted through a personal written survey.

During 2019-2021, the authors conducted a survey in 4 groups of respondents to study the views of 
pharmacy professionals, physicians and consumers of drugs on expert assessment of the effectiveness of combating the spread of CM in Ukraine, as well as ways to improve methods of detection and exactly:

- specialists of the State Medical Service of Ukraine and its territorial bodies -67 experts, both from the central office of the State Medical Service - 16 (23.9\%) and its territorial bodies $-51(76.1 \%)$ from almost all regions of the country;

- specialists of pharmacies in different regions of Ukraine and various forms of ownership - 437 respondents, managers, pharmacists, more than $53 \%$ of respondents work in management positions (heads of pharmacies), which confirms a high level of education, experience in the pharmaceutical industry more than $64 \%$ have more than 10 years;

- doctors of almost all profiles from 27 health care institutions of regional, city and district subordination of one of the regions of Ukraine, which provide both primary and specialized medical care - a total of 821 respondents, including $14.8 \%$ hold managerial positions, $60.8 \%$ have the highest category and $76.2 \%-$ work experience in the medical field for more than 10 years, which confirms their fairly high level of education and qualification;

- consumers of drugs of different ages, places of residence, with different levels of monthly income and education - 600 visitors to 26 pharmacies owned by 13 businesses (licensees) located in the western, eastern, central, northern and southern regions of the country.

The selection of respondents was carried out on the basis of their purposeful selection, taking into account the following basic principles: a high level of education and qualification and the availability of the necessary professional experience of such specialists.

To assess the consistency of the responses of all groups of respondents - pharmaceutical and medical professionals and consumers - on the questionnaire, we calculated the correlation coefficients or consistency of Kendall using the program Statistica.

\section{Research results}

$\mathrm{CMs}$ are illegal and dangerous products because they generally do not meet the basic requirements for drugs - in terms of their effectiveness, safety and quality. They could be ineffective (do not contain active ingredients or contain them in inappropriate quantities, or not be bioequivalent), be dangerous (contain unacceptable amounts of toxic impurities or undeclared active pharmaceutical ingredients (APIs) with other dangerous effects) and / or poor quality (because they are not produced in accordance with the requirements of Good Manufacturing Practice, GMP).

The urgency of the problem of drug falsification for the population sometimes leads to attempts to manipulate politicians (to attract attention and increase the rating of voters) and officials (to obtain additional funding and authority) [21]. That is why it is necessary to understand the real scale of the problem, to assess the level of threat, to develop really effective methods to combat this phenomenon. One of the important elements in this issue is to study the opinions of experts, specialists, consumers of drugs on awareness of the problems of drug falsification. To this end, during 2019-2021 we conducted a comprehensive survey of experts - employees of the central office and territorial bodies of the State Medical Service, employees of pharmacies in different regions of the country, doctors of different profiles and consumers. The conducted statistical calculations show that the correlation between the assessments of the respondents separately for each group is significant, namely:

- for specialists of the State Medical Service -

$\tau=0.15>0.12\left(\mathrm{~T}_{\mathrm{kp}}\right)$;

- for specialists of pharmacies -

$\tau=0.79>0.16\left(\mathrm{~T}_{\mathrm{kp}}\right)$;

- for doctors $-\tau=0.21>0.13\left(\mathrm{~T}_{\mathrm{kp}}\right)$;

- for consumers of drugs $-\tau=0.66>0.2\left(\mathrm{~T}_{\mathrm{kp}}\right)$,

where $\tau$ is the calculated correlation coefficient, $T_{k p}$ is the critical value for the null hypothesis.

Thus, the Kendall coefficient calculated from the obtained data exceeds its critical values, which confirms the consistency of the answers of all groups of respondents in the surveys.

We highlighted, in our opinion, important answers of respondents to similar questions asked during the questionnaire. Thus, the share of counterfeit drugs in the Ukrainian pharmaceutical market at $5 \%$ was estimated by $59.7 \%$ of surveyed experts, $42.3 \%$ of surveyed pharmacy professionals, $11.4 \%$ of doctors and $73.5 \%$ of consumers - visitors to pharmacies, on average $58.5 \%$ of respondents (Fig. 1).

According to the results of the questionnaire, we can say that the share of counterfeit drugs in Ukraine is up to $5 \%$, because the majority of respondents (on average $58.5 \%$ ) answered exactly that. However, it is noteworthy in the survey that four times more pharmacy employees than consumers believe that the share of counterfeit drugs in the pharmaceutical market is from 10 to $50 \%(31.1 \%$ and $8.4 \%$, respectively). Attention should be paid to the opinion of doctors, namely a significant percentage of them $46.9 \%$, who believe the level of falsification from 10 to $50 \%$. Apparently, their opinion is influenced by the almost daily receipt of information from the territorial bodies of the State Medical Service about the need to withdraw from circulation certain batches of drugs that are prohibited for sale.

In our opinion, the answers of the respondents about the signs that can signal that the drug is counterfeit are quite important. Thus, according to most experts, a change in the usual symptoms (taste, smell, colour) may already indicate the falsification of drugs. Instead, for most employees of pharmacies, the main sign of drug falsification was called labelling in a foreign language. Changing the design of packaging (labels) and a significantly lower price is the main sign of falsification of drugs for most consumers (Fig. 2). 


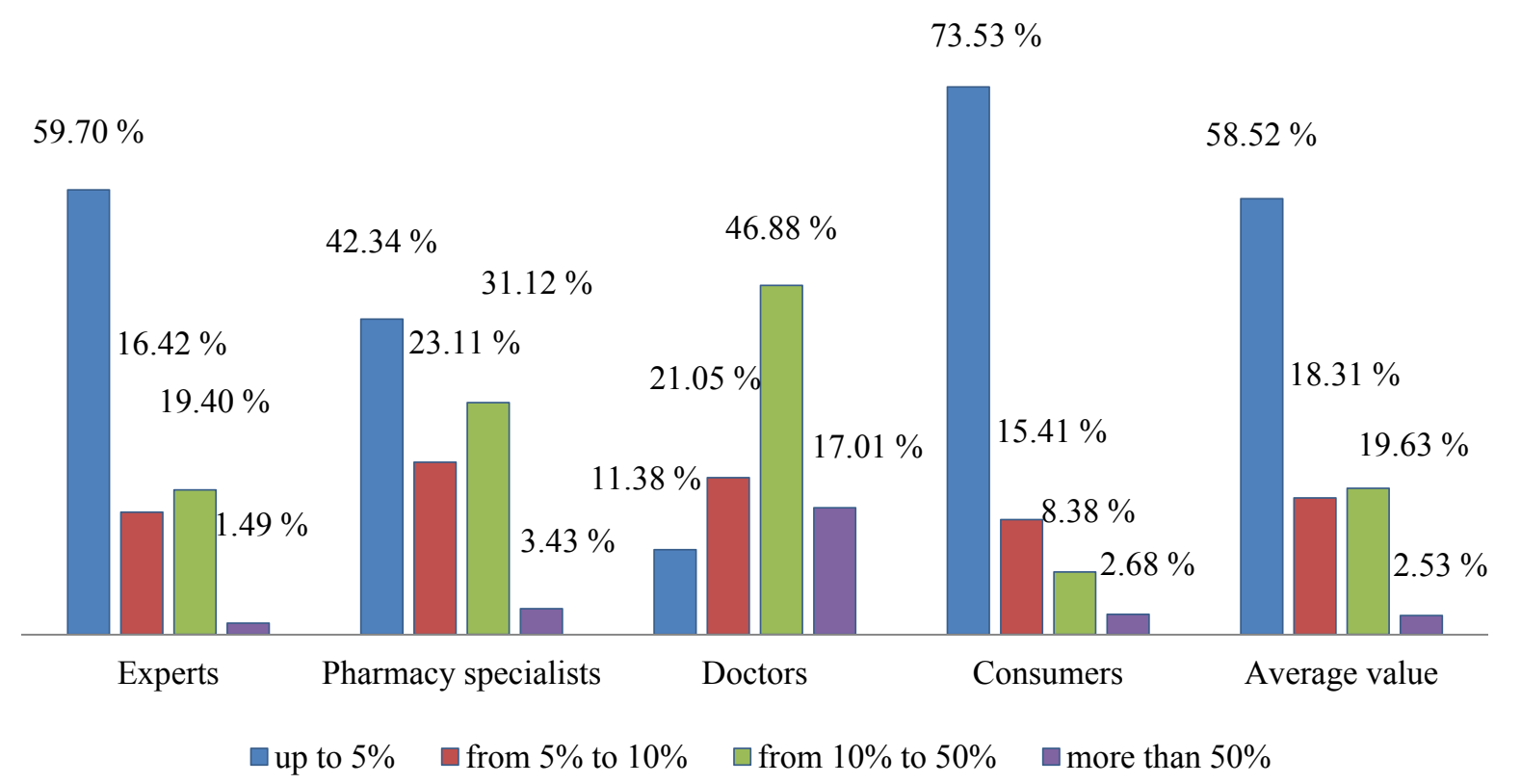

Fig. 1. Survey results on the share of counterfeit drugs in the pharmaceutical market of Ukraine

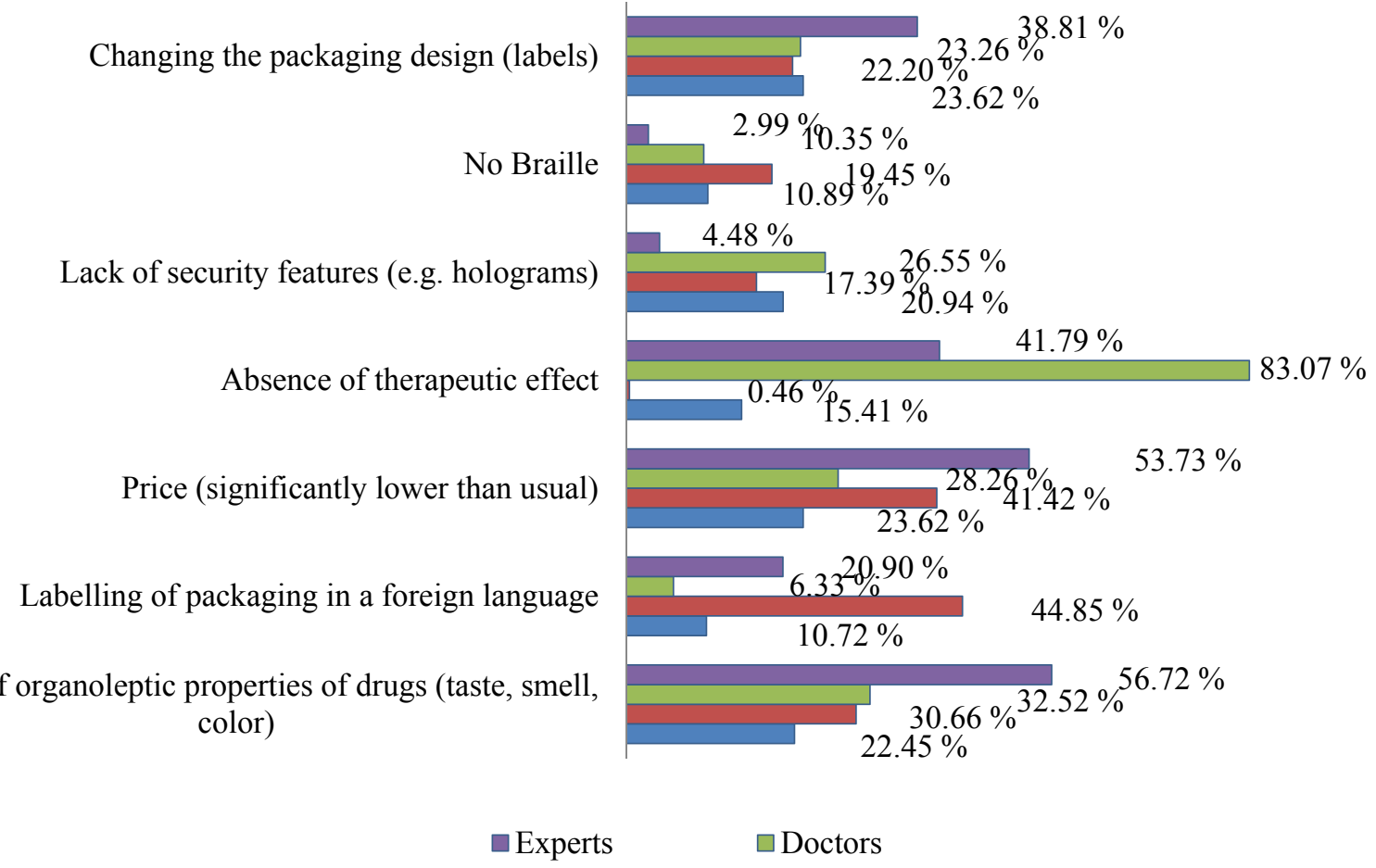

Fig. 2. The results of the survey on the main signs of drug falsification

Only $0.46 \%$ of pharmacies, against $83.1 \%$ of doctors, $41.2 \%$ of experts and $15.4 \%$ of consumers named the lack of therapeutic effect as a sign of drug falsification. Obviously, there is a better awareness of pharmacy staff compared to other categories of respondents with the specifics of drug use (conditions and method of administration, interaction with other drugs, adher- ence to treatment, etc.), which may affect the lack of effect from drug use.

The main sales channels of $\mathrm{CM}$ for experts and pharmacy specialists are e-commerce $(68.7 \%$ and $75.7 \%$, respectively). Instead, the majority of surveyed drug users could not answer this question (60.5\%), Fig. 3. 


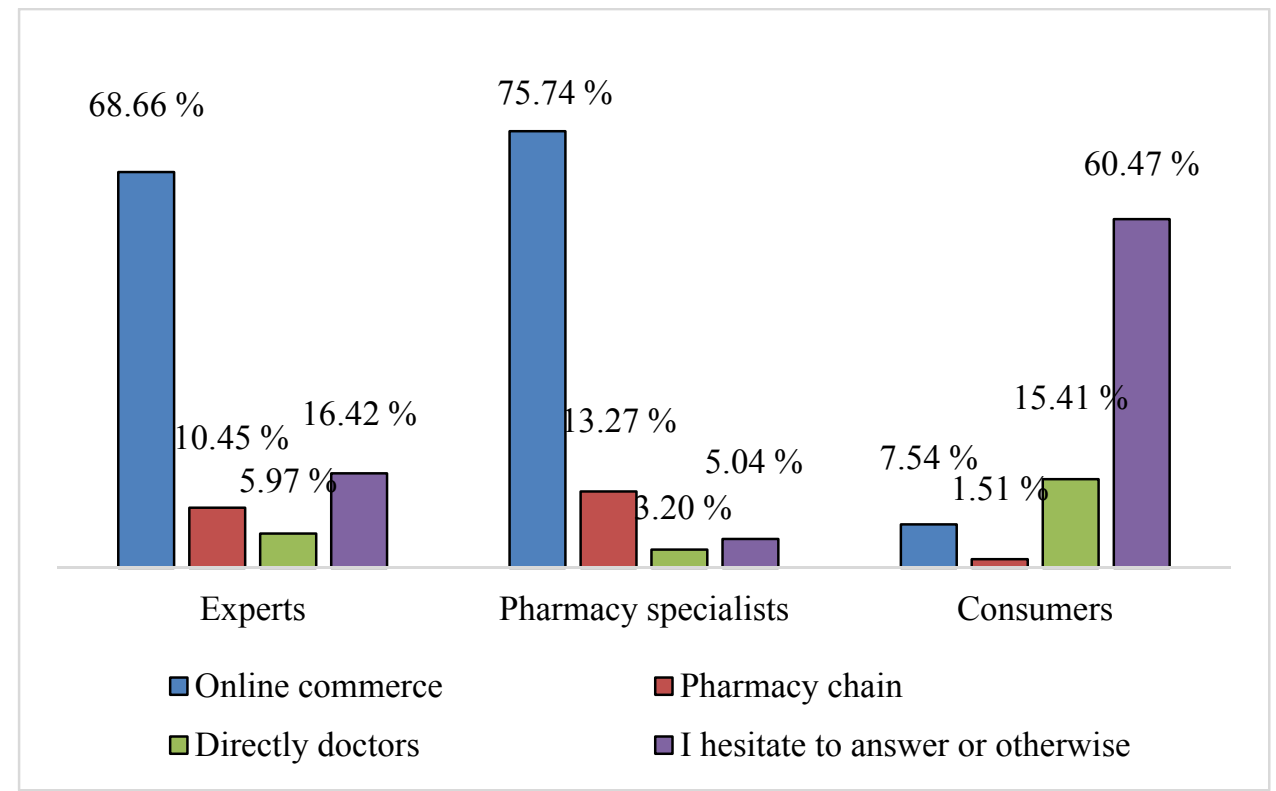

Fig. 3. The results of the survey on the main sales channels of counterfeit drugs

A fairly high percentage of consumer responses $(15.4 \%)$ indicates such a sales channel for counterfeit drugs as doctors themselves. It can be assumed that there are many facts of drug trafficking by doctors during the reception of patients.

Equally important are the respondents' answers to the questions of what methods should be used to detect CM. The majority of experts (over $79 \%$ ) pointed to the need to introduce special protective elements of packaging in the form of $2 \mathrm{~d}$ barcodes, Fig. 4.

Consumers in this case were asked whether they are ready to increase the cost of drugs due to the introduction of additional security features by manufacturers in the form of $2 \mathrm{~d}$ barcodes. The vast majority of consumers of pharmaceutical products (over $68 \%$ ) expect from manufacturers investment and coverage of the cost of additional labelling with control samples of packaging of drugs produced to protect against counterfeiting, without increasing the price of drugs.

From the point of view of the risk of purchasing counterfeit drugs, it was interesting, according to the authors, to ask both employees and consumers of pharmacies in which pharmacies such a risk is higher. It was suggested to choose one answer from the five offered. The results of the answers are shown in Fig. 5.

$79.1 \%$

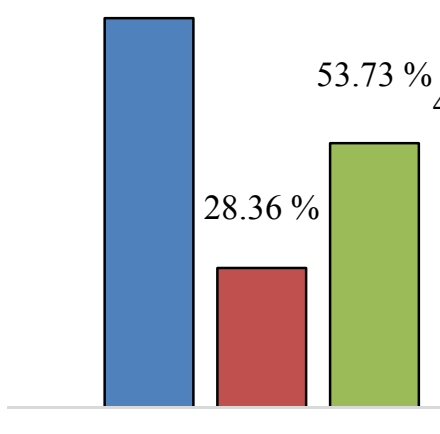

Experts
$39.59 \%$

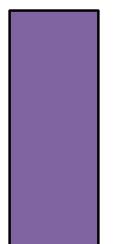

$47.76 \%$

$\square$ Introduction of $2 \mathrm{~d}$ coding of drug packages

$\square$ The use of rapid methods for detecting CM directly in pharmacies

$\square$ Detailed study of accompanying documents

$\square$ Careful visual inspection

Fig. 4. The results of the survey on the main methods that allow to detect counterfeit drugs 
$40.27 \%$

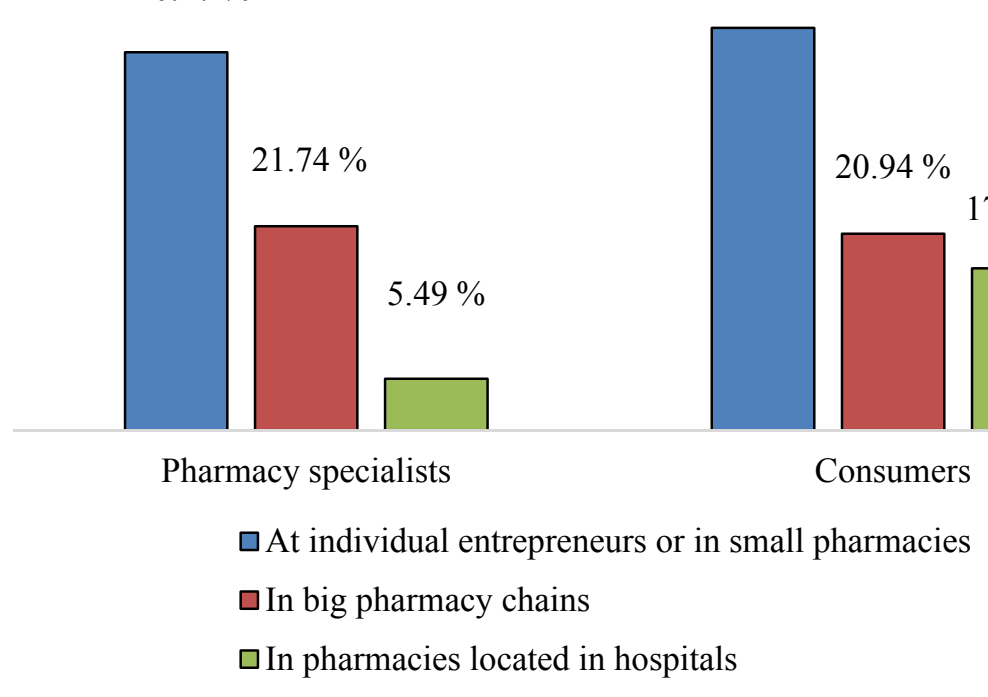

Fig. 5. Survey results on pharmacies that are at greater risk of purchasing counterfeit medicines

Most respondents, as seen in Fig. 5, do not fully trust the pharmacies of individual entrepreneurs or small pharmacy chains $(40.3 \%$ and $42.9 \%)$, which is almost twice as much as the response of respondents to large pharmacy chains (about $21 \%$ ).

\section{Discussion of research results}

At the level of state regulation and control in the field of pharmaceutical activity in Ukraine, a system to prevent the spread of CM has been established, but there is a lack of methods to respond appropriately in a given situation, as well as well-established communication by the state to the general public, the rights and limits of responsibility of doctors, consumers and other entities in the context of combating counterfeiting. The share of $\mathrm{CM}$ in the pharmaceutical market of Ukraine is up to $5 \%$ was estimated by an average of $58.5 \%$ among total surveyed, including $59.7 \%$ of surveyed experts, $42.3 \%$ of surveyed pharmacy professionals, only $11.4 \%$ of doctors and $73.5 \%$ of consumers - visitors pharmacies. According to most experts, a change in the usual symptoms (taste, smell, colour) may already indicate the falsification of drugs. Instead, for most pharmacy professionals, labelling in a foreign language was cited as the main sign of drug falsification. Changing the design of the package (label) and significantly lower price is the main sign of counterfeiting of drugs for most consumers. In our opinion, a rather significant assessment of $83.1 \%$ of physicians about the lack of therapeutic effect as a sign of drug falsification, requires a separate in-depth study of the causes of this situation. The main sales channels for counterfeit drugs for pharmacy experts and specialists consider e-commerce. Instead, the majority of surveyed drug users could not answer this question. Most experts pointed to the need to introduce special security features for packaging in the form of $2 \mathrm{~d}$ barcodes, as the main method to protect the market and facilitate the detection of counterfeit drugs. Most of the surveyed pharmacy workers and consumers believe that the risk of purchasing counterfeit drugs is higher in the pharmacies of individual entrepreneurs or small pharmacy chains.
The main problem that prevents the effective fight against drug falsification by experts was the imperfect legislation $(68.7 \%)$ and lack of funding, low wages of employees of the State Medical Service (61.2\%). More than $86 \%$ of experts identified the abolition of warnings about inspections of pharmaceutical market players as the main direction that needs to be changed in the inspection procedure.

Regarding effective tools in the fight against counterfeit drugs, experts called a significant strengthening of the powers of the regulatory body - following the example of the FDA $(70.1 \%)$, serial independent quality control of imported and manufactured drugs (64.2\%) and strengthening the responsibility for admission to market of drugs with unproven effectiveness (59.7\%). $70.2 \%$ of pharmacy specialists identified batch quality control of medicines in independent laboratories at the stage of wholesale trade, which should be introduced as an additional measure to combat drug falsification.

Comparing the results with the results of the research by other scientists, it should be noted that for example in the publication [7] the author concludes that changes in consumer behaviour over the past decade (e.g. increasing the share of online purchases) have played a key role in the growing problem of counterfeit drugs, which is confirmed by our study, as the main sales channels of CM for experts and pharmacy professionals are ecommerce (68.7\% and $75.7 \%$, respectively).

The authors in the publication [8] proved that between pharmacists and consumers in Qatar, where the survey was conducted, there is no significant difference in how they perceive counterfeit and substandard drugs. Both categories have the same level of susceptibility to counterfeit drugs, as well as a moderate level of vulnerability to counterfeit and substandard drugs. The same conclusions can be drawn from our study, as the answers of respondents (both experts, pharmacy professionals and consumers) about the share of counterfeit drugs in Ukraine (up to $5 \%$ ) were the vast majority.

In a publication [9], the authors concluded from a survey of Swedish doctors that the vast majority of doc- 
tors (over $78 \%$ ) know the term "illegal and falsified drugs", and $36.5 \%$ lack reliable knowledge about the problems of drug falsification. In our study, more than $83 \%$ of physicians in the absence of therapeutic effect of the drugs they prescribed, attributed this to their falsification, and more than $46 \%$ of physicians believed that the proportion of falsified drugs is from 10 to $50 \%$, which significantly different from expert estimates and pharmacy specialists and may also indicate a lack of knowledge about awareness of the problems of drug falsification in Ukraine.

In the publication [10] during the survey of pharmacists in Kazakhstan, the authors claim that the majority of respondents ( $40 \%$ of them) called the most effective way to solve the problem of proliferation of counterfeit drugs was to increase criminal liability for counterfeiting and illegal sale of counterfeit drugs. Instead, in our study, the most effective way to solve this problem was to significantly strengthen the powers of the regulatory body - following the example of the FDA (70.1 \% of experts), and the introduction of serial quality control of drugs in independent laboratories at the wholesale stage (70.2\% of pharmacies).

Study limitations. Questionnaire survey of doctors was conducted on the example of one area due to resource constraints of the authors. Despite the agreement of the respondents of this group, the analysis of the obtained assessments, in our opinion, requires further expansion of the survey of physicians, especially in the regional aspect.

Prospects for further research. Important from the point of view of building a conceptual model for the implementation of state policy to prevent drug falsification are the answers of experts and pharmacy specialists to assess the real state of the fight against drug counterfeiting in Ukraine at this stage. Thus, in particular, among the most important priorities of state policy to combat counterfeit drugs, $74.6 \%$ of experts called improving the system of state control and quality assurance of drugs, and more than $70 \%$ of experts consider it necessary to strengthen responsibility for drug counterfeiting.

Prospects for further research are the introduction of methods of systematic questionnaires for a wider range of respondents (doctors, manufacturers and distributors of pharmaceutical products, importers, public associations, as well as directly citizens).

\section{Conclusions}

During 2019-2021, the authors conducted a comprehensive questionnaire survey of 4 groups of respondents to study the views of pharmacists, physicians and drug users, which provides the most objective data on the spread and evaluation of the effectiveness of CM control. According to the results of the survey, it was found that the most probable share of CM in Ukraine is up to $5 \%$. According to most experts, a change in the usual symptoms (taste, smell, colour) may indicate falsification of drugs. However, respondents' opinions on the main signs of drug falsification differ by groups: for pharmacy professionals it is a marking in a foreign language; for doctors - lack of therapeutic efficacy; for consumers - a change in the design of the package (label) and a significantly lower price.

The main problem in the fight against drug falsification according to experts was imperfect legislation. It was found that the most important priorities of public policy to increase the effectiveness of combating the spread of counterfeit drugs, most respondents consider improving the system of state quality control of drugs, including the introduction of 2-d barcode scanning and strengthening liability for drug falsification. Among the most important tools to minimize the problem of drug counterfeiting is the strengthening of the powers of the regulatory body. Comparison of the obtained results with similar foreign studies indicates their high correlation, and also confirms the feasibility of conducting such systematic surveys for a wider range of respondents - professionals and consumers.

\section{Conflict of interests}

The authors declare there is no conflict of interests.

\section{Financing}

The research was conducted with no financial support.

\section{References}

1. Schneider, M., Ho Tu Nam, N. (2020). Africa and counterfeit pharmaceuticals in the times of COVID-19. Journal of Intellectual Property Law \& Practice, 15 (6), 417-418. doi: http://doi.org/10.1093/jiplp/jpaa073

2. Counterfeit drugs 2021: Statistics and Facts on how Blockchain can fight the pandemic? (2021). Available at: https://vaultsecurity.io/counterfeit-drugs-2021

3. A study on the public health and socioeconomic impact of substandard and falsified medical products (2017). WHO. Available at: https://www.who.int/medicines/regulation/ssffc/publications/SE-Study_EN_web.pdf?ua=1

4. Ciapponi, A., Donato, M., Gülmezoglu, A. M., Alconada, T., Bardach, A. (2021). Mobile apps for detecting falsified and substandard drugs: A systematic review. PLOS ONE, 16 (2), e0246061. doi: http://doi.org/10.1371/journal.pone.0246061

5. Chitre, M., Sapkal, S., Adhikari, A., Mulla, S. (2019). Monitoring Counterfeit Drugs using CounterChain. 2019 International Conference on Advances in Computing, Communication and Control (ICAC3). doi: http://doi.org/10.1109/ icac347590.2019.9036794

6. Felicity, T. (2021). Securing Each Dose: Reducing Falsification Risk with Dosage Level Authentication. Pharmaceutical Technology, 2, 29-31.

7. May, C. (2019). Counterfeit medicines - fake drugs and falsified medicines - are endangering lives. Available at: https://www.pharmout.net/counterfeit-medications-global-statistics/

8. Alfadl, A., Ibrahim, M., Maraghi, F., Mohammad, K. (2016). An examination of income effect on consumers' ethical evaluation of counterfeit drugs buying behaviour: a cross-sectional study in Qatar and Sudan. Journal of Clinical and Diagnostic Research, 10 (9), IC01-IC04. doi: http://doi.org/10.7860/jcdr/2016/19526.8410 
9. Funestrand, H., Liu, R., Lundin, S., Troein, M. (2019). Substandard and falsified medical products are a global public health threat. A pilot survey of awareness among physicians in Sweden. Journal of Public Health, 41 (1), e95-e102. doi: http://doi.org/10.1093/pubmed/fdy092

10. Tulegenova, A. R., Dilbarhanova, J. R., Sokurenko, I. A. (2018). Analysis of the results of pollution of pharmaceutical workers on the problem of falsification of pharmaceutical drugs and their illegal turnover on the pharmaceutical market of the Republic of Kazakhstan. Management, economics and quality assurance in pharmacy 1 (53), 63-71. doi: http://doi.org/10.24959/uekj.18.7

11. Gutorova, N. (2019). Vidpovidalnist za falsyfikatsiiu likarskykh zasobiv: chy stvorena v Ukraini nalezhna pravova baza? Apteka, 2 (1173). Available at: https://www.apteka.ua/article/485029

12. Galt, K., Fuji, K., Kaufman, T., Shah, S. (2019). Health Information Technology Use and Patient Safety: Study of Pharmacists in Nebraska. Pharmacy, 7 (1), 7. doi: http://doi.org/10.3390/pharmacy7010007

13. Cvetanovski, F., Asanova, B., Brezovska, K. (2016). Comparative analysis of EU and USA falsified medicine legislation. Macedonian pharmaceutical bulletin, 62, 681-682. Available at: https://core.ac.uk/download/pdf/80818116.pdffpage=681

14. Yolanda, R., Jean, C., Casauay, B., Paul I. (2016). Addressing the Barriers to Effective Monitoring, Reporting and Containment of Spurious/ Substandard/ Falsely-labelled/ Falsified/ Counterfeit Medical Products through Sustainable Multi-stakeholder Collaboration and Community/ Consumer-based Interventions. Final Report. Available at: https://www.who.int/medicines/areas/coordination/SSFFC_Report.pdf

15. Houlton, S. (2018). Tackling the problem of falsified medicines in the UK. Prescriber, 29 (7), 33-35. doi: http://doi.org/10.1002/psb.1690

16. Laín Abril, J., Holt, D. W. (2016). Falsified Medicines in the European Union and North America: What are we doing to Protect Public Health? Journal of Pharmacovigilance, 4 (3). doi: http://doi.org/10.4172/2329-6887.1000213

17. Cuomo, R. E., Mackey, T. K. (2014). An exploration of counterfeit medicine surveillance strategies guided by geospatial analysis: lessons learned from counterfeit Avastin detection in the US drug supply chain. BMJ Open, 4 (12), e006657. doi: http://doi.org/10.1136/bmjopen-2014-006657

18. Counterfeit medicine in America 9th Annual Drug Abuse Symposium (2018). Available at: https://www.in.gov/bitterpill/files/Safdar-Counterfeit-IN-AG-Opioid-Summit-2018-10-29-FINAL.pdf

19. Counterfeit medications a growing problem in Canada, warns new report (2018). Available at: https://www.ctvnews.ca/health/counterfeit-medications-a-growing-problem-in-canada-warns-new-report-1.3795239

20. Hensey, C. C., Gwee, A. (2016). Counterfeit drugs: an Australian perspective. Medical Journal of Australia, 204 (9), 344-344. doi: http://doi.org/10.5694/mja16.00105

21. Sur, S. (2021). Stvorennia, rozvytok i zanepad systemy borotby z falsyfikatsiieiu likarskykh zasobiv v Ukraini. Apteka, 3 (1274). Available at: https://www.apteka.ua/article/581247

Received date 01.07.2021

Accepted date 19.10.2021

Published date 29.10.2021

Serhii Lebed, Postgraduate Student, Department of Organization and Economics of Pharmacy, National University of Pharmacy, Pushkinska str., 53, Kharkiv, Ukraine, 61002, Head of Service, State Service for Medicines and Drug Control in the Rivne region, 16 Lypnia str., 38, Rivne, Ukraine, 33028

Alla Nemchenko*, Head of Department Department of Organization and Economics of Pharmacy, National University of Pharmacy, Pushkinska str., 53, Kharkiv, Ukraine, 61002

*Corresponding author: Alla Nemchenko,e-mail: asnemchenko@ukr.net 